has shown that bursts in isolated cortex are maintained by a reverberating network of similar neurones. The results reported here make it difficult to see how such a net could be responsible for bursts in the intact cortex, for if the cell possesses classical properties, one would expect that local polarization would alter the threshold of the cell to synaptic bombardment from the net, thus changing the frequency of firing within bursts. We have compared the lengths of inter-burst intervals with the duration and number of action potentials in the bursts preceding them and found no correlation. Thus the burst mechanism appears to be independent of the mechanism which generates spike discharges during bursts.
A more detailed account of this work proposing a mathematical model of the signal is in the press. Work is in progress which may lead to a further clarification of the mechanisms involved and of the role of very short intervals.

This work has been carried out as part of the research programme of the National Physical Laboratory, and is published by permission of the Director.

'Martin, A. R., and Branch, C. L., J. Neurophysiol., 21, 368 (1958),

2 Girstein, G. L., and Klang, N. Y.-S., Biophys. J., 1, 15 (1960).

Burns, B. D., and Grafstein, B., J. Physiol., 118, 412 (1952),

- Burns, B. D., J. Physiol., 127, 168 (1955).

'Burns, B. D., and Smith, G. K., J. Physiol., 164, 238 (1962).

\title{
COUPLING OF CYCLIC CHEMOTHERAPEUTIC COMPOUNDS TO IMMUNE GAMMA-GLOBULINS
}

\author{
By Dr. S. DeCARVALHO, Dr. H. J. RAND and A. LEWIS \\ Laboratory of Cancer Virology and Immunology, Rand Development Corporation, \\ Cleveland, Ohio
}

B virtue of their serological specificity, immune $\gamma$-globulins may serve as 'guided missiles' to carry and deliver therapeutic agents to target cells containing the speoific antigens. This article deals with some of the chemical problems involved in the coupling of therapeutio agents to $\gamma$-globulins.

The following procedure represents an adaptation of the method utilized by Heidelberger ${ }^{1}$ to couple $\beta$-naphthol 3:6 sodium disulphonate $(R$-salt $)$ to crystalline egg albumin, and by Kabat ${ }^{2,8}$ to couple the same dye to horse serum albumin. Mathé et al. make quick reference to having coupled methotrexate to rabbit hyperimmune $\gamma$-globulin by diazotization 4 , but no details are given.

The method here described was examined in detail and criteria for the end-points of each step of the coupling were developed.

The following materials were used:

Therapeutic compounds. Methotrexate (courtesy of Dr. J. M. Ruegsegger, Lederle Laboratories, Pearl River, New York) (A-methopterin) 4-amino-N ${ }^{10}$-methyl pteroylglut. amic acid (MTX), lot No. 1260-01; uracil mustard (courtesy of Dr. H. Petering, Upjohn Co., Kalamazoo), lot. No. $2358 K(\mathrm{UM})$; 5 -fluorouracil (courtesy of Dr. G. Zbinden, Hoffmann-La Roche, Inc., Nutley, New Jersey), lot No. 009122 (5-FU); tetracycline ('Achromycin V', Lederle), lot No. 4859-23; 6-mercaptopurine hydrate (Nutritional Biochemical Co., Cleveland, Ohio), lot No. 4554 (6MP); chlorambucil (Nutritional Biochemical Co.), lot No. 9981; 'Thio-Tepa' (Lederle), lot No. 4650-91.

Gamma-globulins. Human $\gamma$-globulin from pooled serum (Cutter Laboratories, Berkeley, Calif.), lot No. G6083 (HSGG); horse anti-tumour hyperimmune $\gamma$-globulin, lot No. 257-29 (ref. 5) (HTUGG); horse anti-leukæmia hyperimmune $\gamma$-globulin, lot No. 567-M1-21 (ref. 5) (HLKGG).

Even though there was successful coupling with all the therapeutic compounds listed, methotrexate, uracil mustard and 5-FU were the only ones investigated in detail.

The coupling develops through the following three steps: (1) dirzotization of benzidine; (2) coupling of the therapeutic compound to diazotized benzidine; (3) coupling of the compound obtained in (2) to $\gamma$-globulin.

The temperature of all operations is $7^{\circ}-8^{\circ} \mathrm{C}$. All reagents are added drop by drop with constant stirring.

Step $I$. In a $100-\mathrm{ml}$. beaker place $37.0 \mathrm{ml}$. of benzidine reagent $(720.0 \mathrm{mg}$ of analytical grade benzidine in $6.50 \mathrm{ml}$. of $6 \mathrm{~N}$ hydrochloric acid added to $31.50 \mathrm{ml}$. of distilled water). Cool to $8^{\circ} \mathrm{C}$ in a bath of ice water oversaturated with sodium chloride. Below $6^{\circ} \mathrm{C}$ this reagent freezes. Over a period of 2 min add $14.00 \mathrm{ml}$. of pre-cooled sodium nitrite reagent $(1.30 \mathrm{~g}$ of sodium nitrite in $32.0 \mathrm{ml}$. of distilled water). The end-point was determined in the following way. Immediately after each eddition of 0.1 -

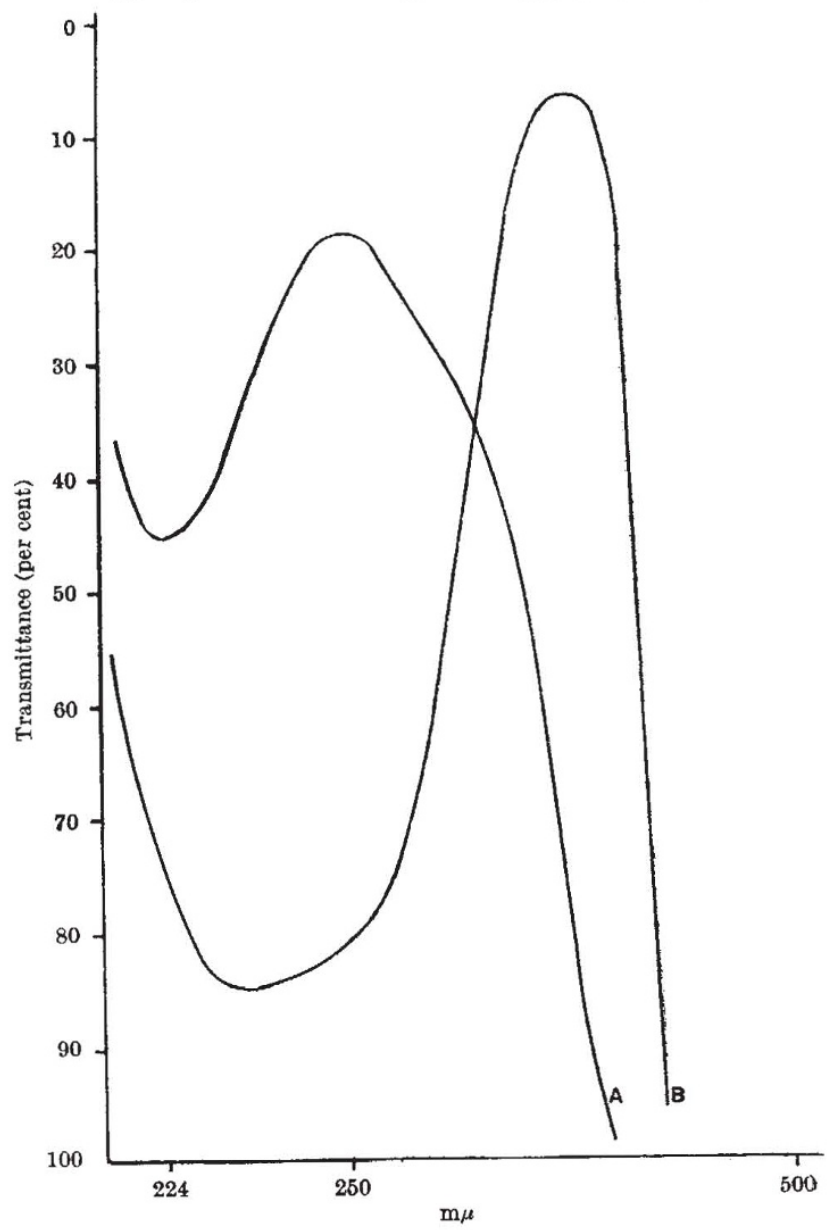

Fig. 1. $A, 2 \mu \mathrm{g} / \mathrm{ml}$. benzidine solution in $6 \mathrm{~N}$ hydrochloric acid at $p$ H 1.0 ; maximum absorption peak, $250 \mathrm{~m} \mu$; minimum absorption eak, $224 \mathrm{~m} \mu$. $\mathcal{B}$, diazotized benzidine in solution at $p \mathrm{H} 1.0 ; \operatorname{maxim}$ 
$0.2 \mathrm{ml}$., a piece of starch iodide paper immersed in the solution turns dark blue. This indicates excess of nitrite just added. After stirring for $10 \mathrm{sec}$, the nitrite is partly eombined, partly eliminated and the iodide paper does not discolour. The end-point is indicated by persistence of the blue discoloration of the paper even after stirring for 10-20 sec. However, prolonged stirring (10 min) will again prevent blueing of the paper following volatilization of excess nitrous acid. This product is light green in colour. The colour of the tetrazobenzidine is brought out by addition of sodium acetate $(4.50 \mathrm{~g}$ of sodium acetate in $10.0 \mathrm{ml}$. of water). In a $250-\mathrm{ml}$. beaker place $20.0 \mathrm{ml}$. of pre-cooled acetate reagent. With constant stirring, add in $1 \mathrm{~min}$ the tetrazobenzidine. The colour becomes first light yellowish-green and in 3-5 min changes to yellowish-brown (weak-tea colour). Diazotization of benzidine results in the changes in the ultra-violet absorption spectra indicated in Fig. $1 A$ and $B$.

Determination of end points for Steps II and III resulted from the following observations. Keeping the amount of diazobenzidine constant, different amounts of the therapeutic agent were tried to bind to the azobenzidine. It was noticed that at low levels of therapeutic compound the resulting substance when coupled to the $\gamma$-globulin produced gelation of the protein while high levels of the cyclic compound prevented gelation.

It was then found that small amounts of tetrazobenzidine alone produced constantly gelation of the $\gamma$-globulin.

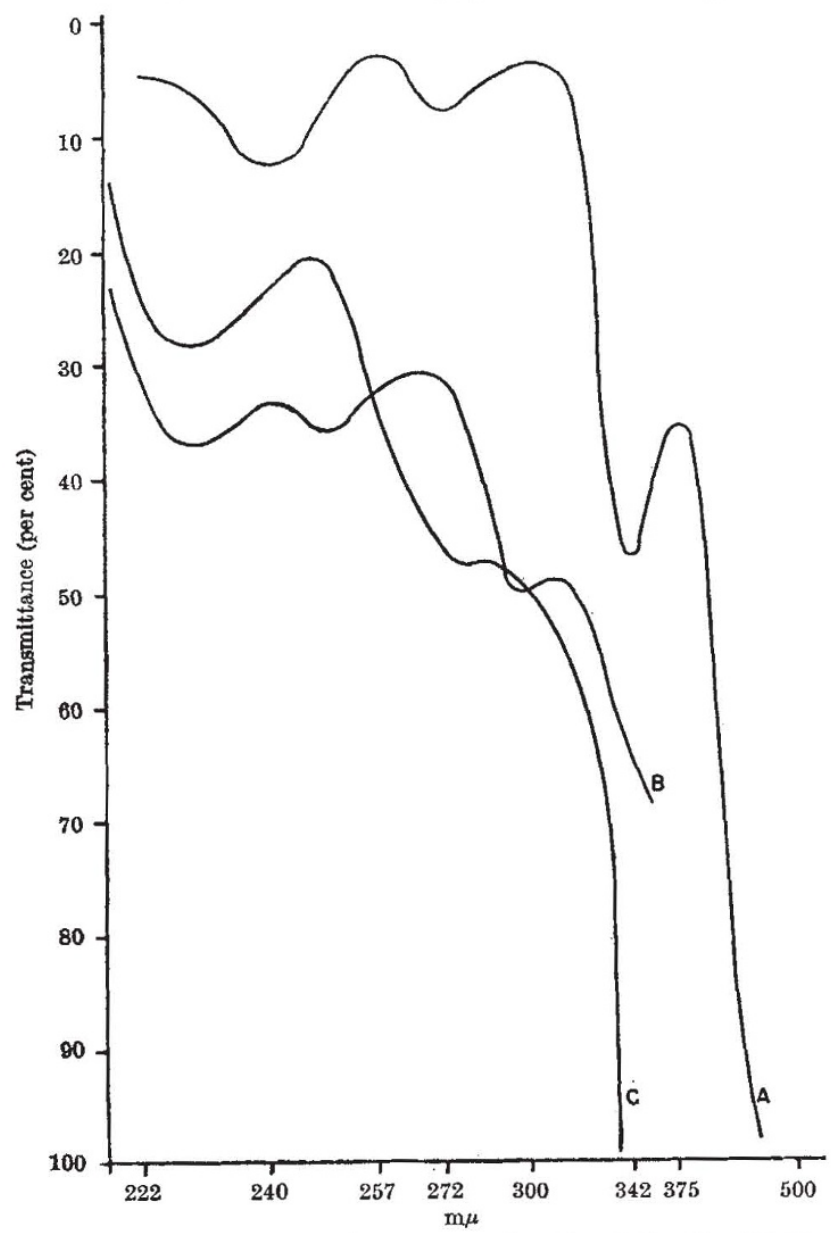

Fig. 2. $A, 9 \mu \mathrm{g} / \mathrm{ml}$. solution of methotrexate in sodium hydroxide $p H \mathbf{H} 14 \cdot 0$ at $25^{\circ} \mathrm{C}$; absorption peaks, maximum, $375 \mathrm{~m} \mu$; minimum, $342 \mathrm{~m} \mu$; maximum, $300 \mathrm{~m} \mu ;$ minimum, $272 \mathrm{~m} \mu$; maximum, $247 \mathrm{~m} \mu$; minimum, $240 \mathrm{~m} \mu$. $B$, diazo-diphenyl-dlazo-nethotrexate (azotrexate) solution at $p$ H 2.5: absorption peaks, maximum, $369 \mathrm{~m} \mu$; minimum, $340 \mathrm{~m} \mu$; maximum, $202 \mathrm{~m} \mu$; minimum, $271 \mathrm{~m} \mu$; maximum, $259 \mathrm{~m} \mu$; minimum, $244 \mathrm{~m} \mu$. C, $1 / 120$ dilution of a $y$-globulin-azotrexate ('Gazotrexate- $L$ ') solution containing $2.4 \mathrm{mg} / \mathrm{ml}$. of methotrexute and $77 \mathrm{mg} / \mathrm{ml}$. of horse anti-leukæmia $\gamma$-globulin at $p \mathrm{H} \quad 8.0$; absnrption peaks, maximum, $389 \mathrm{~m} \mu$; minimum, $345 \mathrm{~m} \mu$; maximum, $280 \mathrm{~m} \mu$; ininimum, $250 \mathrm{~m} \mu$

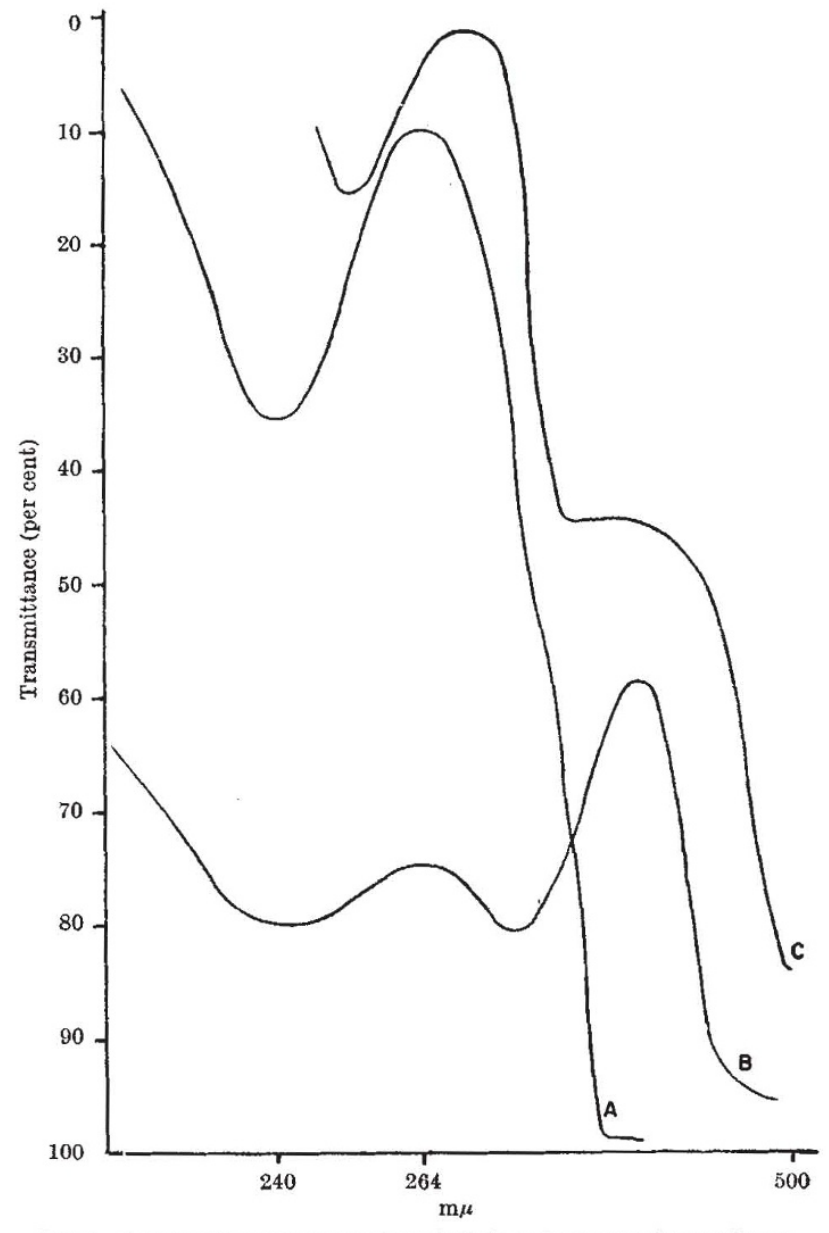
Fig. 3. $A, 0 \cdot 00094$ per cent solution of $5-\mathrm{FU}, p H \mathrm{H} \cdot 5$; maximum absorp-
tion peak, $264 \mathrm{~m} \mu$; minimum absorption peak, $240 \mathrm{~m} \mu$. $B$, solution of diazo-diphenyl-diazo-5-FU (azo-5-FU), $p$ H $5 \cdot 5$; absorption peaks, maximum, $340 \mathrm{~m} \mu$; minimum, $290 \mathrm{~m} \mu$; maximum, $264 \mathrm{~m} \mu$; minimum $240 \mathrm{~m} \mu . \quad C, 1 / 133$ dilution of a $\gamma$-globulin-azo-5-FU ('Gazo-5-FU-T') solution containing: $1.1 \mathrm{mg} / \mathrm{ml}$. of $5-\mathrm{FU}$ and $66 \mathrm{mg} / \mathrm{ml}$. of anti-tumour horse $\gamma$-globulin at $p H$ 8.0 after dialysis ; absorption peaks, maximum, $340 \mathrm{~m} \mu$; minimum, $320 \mathrm{~m} \mu$; maximum, $280 \mathrm{~m} \mu$; minimum, $250 \mathrm{~m} \mu$

This led to the hypothesis that tetrazobenzidine acted as a divalent link between the polypeptide chains of $\gamma$-globulin (a), leading to its copolymerization?.

(a)

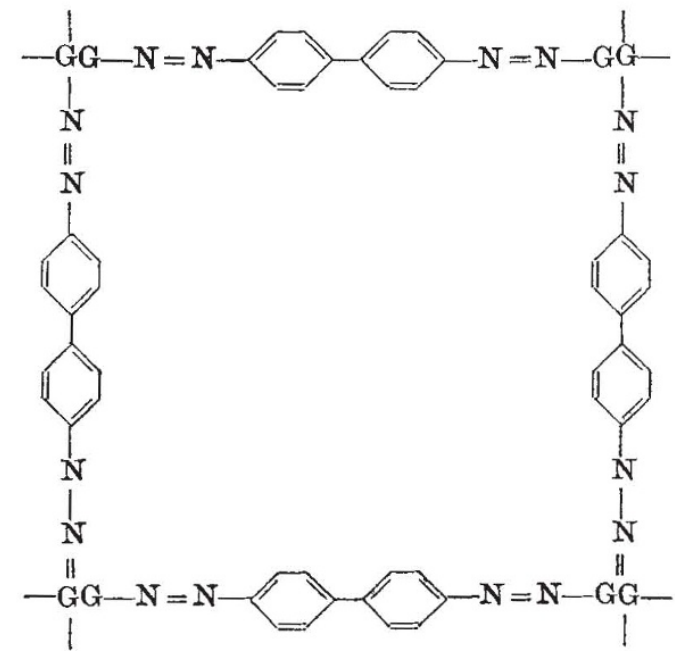

On the other hand, the coupling of the tetrazobenzidine to the therapeutic compound $(R)$ would either make the azobenzidine non-reactive $(b)$ with $\gamma$-globulin 


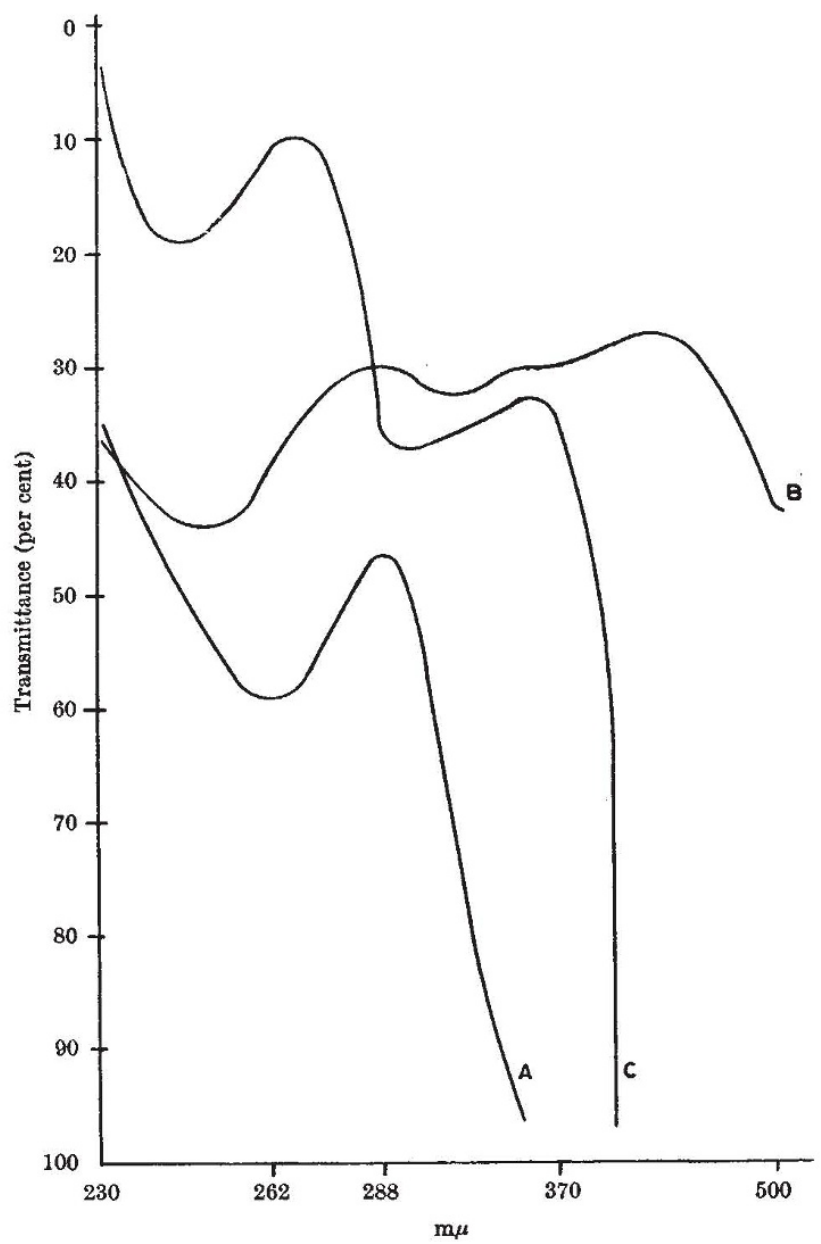

Fig. 4. $A, 10 \mu \mathrm{g} / \mathrm{ml}$. solution of uracil mustard, $p$ H 11.0; maximum absorption peak, $280 \mathrm{~m} \mu$; minimum absorption peak, $262 \mathrm{~m} \mu$. $B$, solution of diazo-diphenyl-diazo-uracil mustard (azoum), $p$ H $2 \cdot 5$; absorption peaks; maximum, $365 \mathrm{~m} \mu$; minimum, $276 \mathrm{~m} \mu$; maximum, $252 \mathrm{~m} \mu$; mintmum, $230 \mathrm{~m} \mu . C, 1 / 20$ dilution of a $\gamma$-globulin-azoum ('Gazoum $L^{\prime}$ ') solution containing: $2.0 \mathrm{mg} / \mathrm{ml}$. of UM and $67 \mathrm{mg} / \mathrm{ml}$. of anti-leukæmi horse $\gamma$-globulin at $p H$ H 80 ; absorption peaks, maximum, $390 \mathrm{~m} \mu$ minimum, $320 \mathrm{~m} \mu$; maximum, $280 \mathrm{~m} \mu$; minimum, $250 \mathrm{~m} \mu$

$$
R-\mathrm{N}=\mathrm{N}-\Longleftrightarrow-\longrightarrow \mathrm{N}=\mathrm{N}-R
$$

or univalent (c)

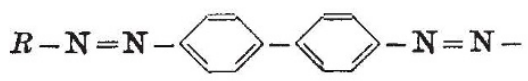

This hypothesis was confirmed by dialysing the final coupled compound extensively against buffered saline and determining the elimination of unbound $R$ compound when gelation did not occur. By trial and error the ideal proportions that give a univalent compound $(c)$ were determined for each therapeutic agent.

At these proportions no gelation of the protein occurs and only traces of the diazotized agent are found in the buffer outside the dialysing bag.

The following are the proportions found for the three compounds examined. Methotrexate: $600 \mathrm{mg}$ benzidine, $720 \mathrm{mg} \gamma$ globulin, 1,920 mg; uracil mustard: 600 mg benzidine, $720 \mathrm{mg} \gamma$-globulin, 1,920 mg; 5-fluorouracil: $360 \mathrm{mg}$ benzidine, $720 \mathrm{mg}$ $\gamma$-globulin, $1,920 \mathrm{mg}$.
Step II. To the tetrazobenzidine add the proper amount of the therapeutic agent over a period of $2 \mathrm{~min}$. The mixture slowly acquires a deep brownish-red colour. Allow to stand $7 \mathrm{~min}$ at $8^{\circ} \mathrm{C}$. To complete coupling add $10.0 \mathrm{ml}$. of $8 \mathrm{~N}$ potassium carbonate. Methotrexate and 5-FU give a strong coffee colour, uracil mustard a redorange or brick. The solutions are left stationary at $8^{\circ} \mathrm{C}$ for $1 \mathrm{~h}$ in the dark.

Figs. $2 A, 2 B, 3 A, 3 B, 4 A$ and $4 B$ give the changes in the ultra-violet absorption spectra following these reactions. These spectra were utilized to identify these compounds in the buffer outside the dialysis bag of the final compound.

Step III. The $\gamma$-globulin reagent is prepared by adding to $120 \mathrm{ml}$. of 16 per cent solution of $\gamma$-globulin in isotonic saline $20.0 \mathrm{ml}$. of a solution containing $11.05 \mathrm{~g}$ of potassium carbonate. The protein solution is placed in a $250-\mathrm{ml}$. beaker and the azotized drug is added slowly. The stirring at this step must be very gentle to avoid denaturation by foaming. At the end, $10.0 \mathrm{ml}$. of $8 \mathrm{~N}$ potassium carbonate is added. The colour of the coupled $\gamma$-globulin is essentially the same as that of the tetrazo compound, but the ultra-violet spectrum is specific for each one of them (Figs. $2 C, 3 C$ and $4 C$ ).

In all the spectra of the Gazo-products the presence of $\gamma$-globulin $(280 / 250 \mathrm{~m} \mu)$ is recognized.

The sequence of the three steps is exemplified for methotrexate in Fig. 5. The exact position of the coupling in the therapeutic compound is not known.

The final product is dialysed against isotonic sodium chloride. The extent of the dialysis is determined by examining the ultra-violet absorption spectra of samples of the saline. After dialysis, the volume is adjusted to near the original concentration of the $\gamma$-globulin by freeze-evaporation. In addition to removing undesirable chemicals in the preparation, dialysis proves that the therapeutic agent is tightly bound to the $\gamma$-globulin since the colour of this persists after dialysis. Further proof of this tight binding is provided by precipitation of the $\gamma$-globulin with ethanol, desalting or 15 per cent trichloroacetic acid (TCA), all of which give a dark brown protein precipitate and clear supernatant. This precipitate retains the colour after extensive washing. The methotrexatecoupled $\gamma$-globulin has the expected $R_{F}$ value on paper electrophoresis for $\gamma$-globulin in addition to the characteristic colour, ultra-violet absorption and fluorescence of methotrexate. These same properties were observed on precipitation bands in agar obtained when the coupled immune $\gamma$-globulins were reacted with the corresponding antigens.

Attempts are now being made to couple the same compounds on active antibody sites obtained from proteolytic and sulphitolytic treatment of the $\gamma$-globulins.

Deproteinization by TCA can be used as a method to determine quantities of unbound therapeutic compound.
$\mathrm{H}_{2} \mathrm{~N} \longrightarrow-\mathrm{NH}_{2}+2 \mathrm{NaNO}_{2}+4 \mathrm{HCl} \longrightarrow \mathrm{ClN}=\mathrm{N} \longrightarrow-\mathrm{N}=\mathrm{NCl}+2 \mathrm{NaCl}+4 \mathrm{H}_{2} \mathrm{O}$

\section{BENZIDINE}

TETRAZO-BENZIDINE-CHLORIDE

Fig. 5. Coupling of methotrexate to horse $\gamma$-globulin by diazotization (gazotrexate) 
Sterility, safety, purity, pyrogenicity tests and vialing are performed by conventional methods ${ }^{6}$.

Wo thank Dr. R. Duschinsky for his comments.

${ }^{1}$ Heidelberger, M., Kendall, F. E., and Soo Hoo, C. M., J. Exp. Med., 58, 137 (1933).

${ }^{2}$ Kabat, E. A., and Heidelberger, M., J. Exp. Med., 66, 229 (1937).

\author{
${ }^{3}$ Kabat, E. A., and Mayer, M. M., Experimental Immunochemistry (Ch. C. \\ Thomas, Springfield, Ill., 1958). \\ - Mathé, G., Tran Ba Loc, and Bernard, J., C. R. Soc. Biol., Paris, 246, 1626 \\ (1958). \\ ${ }^{5}$ DeCarvalho, S., Cancer, 16, 300 (1963). \\ - Public Health Service Regulations, Biological Products Title 42, Part 73, \\ Pub. No. 437 (U.S. Dept. of Health, Education and Welfare, Bethesda,
Md., 1962). \\ " DeCarvalho, S., Lewis, A., Rand, H. J., and Uhrick, J. (in the press).
}

\title{
A MOLECULAR MECHANISM OF SICKLED ERYTHROCYTE FORMATION
}

\author{
BY Dr. MAKIO MURAYAMA
}

Laboratory of Physical Biology, National Institute of Arthritis and Metabolic Diseases, National Institutes of Health, Bethesda, Maryland

A

SUB-MOLECULAR mechanism for gel formation in sickle-cell hæmolysate was presented in a previous report $^{1}$; it was suggested that at $38^{\circ}$ the amino-terminal valyl residue interlocks with the genetically interchanged valyl residue in the $\beta$-chain, allowing cyclization from carbonyl of the first valyl to the $\mathrm{NH}$ of the fourth threonyl by hydrogen bonding as shown schematically here:

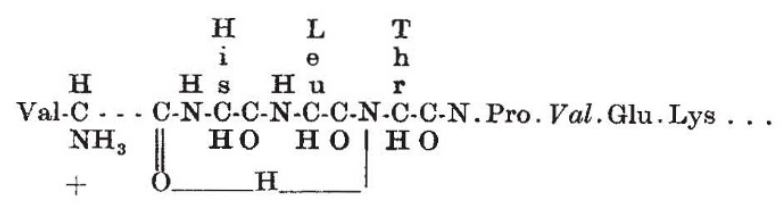

This suggestion was made in order to account for the change in optical rotatory dispersion with temperature. The adequacy of the proposed conformation could be further evaluated by using a simple hydrophobic molecule resembling the valyl side chain, propane. I wish to report here that propane, ethane and methane were found to 'unsickle' sickled erythrocytes containing Hb-S (sicklecell hæmoglobin). These compounds can also prevent and/or reverse the gel formation of deoxygenated $\mathrm{Hb}-\mathrm{S}$ hæmolysate at $38^{\circ}$. The magnitude of the optical rotation is reduced by these compounds also. These observations are consistent with the hypothesis previously presented for a sequence of events which led to sickled erythrocyte formation.

Conventional methods were used to observe microscopically the phenomenon of sickling. Erythrocytes were deoxygenated using a 4 per cent sodium metabisulphite $\left(\mathrm{Na}_{2} \mathrm{~S}_{2} \mathrm{O}_{5}\right)$ aqueous solution added to blood from patients known to be homozygous for $\mathrm{Hb}-S$. A small aliquot of blood was placed in a 50-ml. round-bottomed flask which was fitted with a stopper and tubing connected to a propane tank. Propane was allowed to dissolve under a pressure of about $300 \mathrm{~mm}$ mercury at $38^{\circ}$. The gel-formation experiment at $38^{\circ}$ was performed in a small vial fitted with a serum-bottle rubber cap pierced by 2 hypodermic needles as previously described ${ }^{2}$. The optical rotatory dispersion data were obtained on the instrument used in the previous report ${ }^{1}$.

No sickling was observed when the blood specimen from a patient known to be homozygous of $\mathrm{Hb}-\mathrm{S}$ was treated with propane. Several samples were used in this investigation, each specimen from a different patient. In the untreated aliquots serving as controls nearly 100 per cent sickling was found when deoxygenated with sodium metabisulphite. Essentially no sickling was observed when methane or ethane was substituted for propane. These simple molecules can also liquefy the gel of deoxygenated $\mathrm{Hb}-\mathrm{S}$ hæmolysate and also prevent its formation. The changes in optical rotation at $38^{\circ}$ normally observed in $\mathrm{Hb}-\mathrm{S}$ hæmolysate are reduced in the presence of propane. $\mathrm{Hb}-C_{\text {Georgetown containing erythrocytes do not }}$ 'unsickle' when treated with propane.

A sub-molecular mechanism of sickled erythrocyte formation was investigated because it was observed that a deoxygenated $\mathrm{Hb}-\mathrm{S}$ hæmolysate of sufficient concentration gels at $38^{\circ}$, but liquefies reversibly on cooling to about $0^{\circ}$ (ref. 2). Hæmolysates of normal hæmoglobin $(\mathrm{Hb}-A)$ do not gel at all. The fact that the $\mathrm{Hb}-S$ hæmolysate gel melts reversibly suggested that the molecules must undergo a dynamic conformational (architectural) change of some sort with temperature. The optical rotatory dispersion study revealed that the amplitude of the Cotton effect in the green region as well as in the Soret region is increased reversibly four-fold when the deoxygenated $\mathrm{Hb}-\mathrm{S}$ solution is warmed to $38^{\circ}$. The optical rotation of a solution of $\mathrm{Hb}-A$, on the other hand, was found to change but slightly with temperature.

It is known that the only chemical difference between the normal hæmoglobin (Hb- $A$ ) and the sickle-cell hæmoglobin $(\mathrm{Hb}-\mathrm{S})$ is in one amino-acid residue in the $\beta$-chain ${ }^{3,4}$. The locus of the genetic alteration is in the 6 th residue from the $N$-terminus. The $\alpha$-chain of both hæmoglobins has the same amino-acid sequence. The amino-acid sequence of the first 8 residues from the amino terminus of the $\beta$-chains for $\mathrm{Hb}-A, \mathrm{Hb}-\mathrm{S}, \mathrm{Hb}-C, \mathrm{Hb}-G$ and $\mathrm{Hb}-C_{\text {Georgetown }}$ is as follows:
$\mathrm{Hb}-A$
Val.His.Leu.Thr.Pro.Glu.Glu.Lys ....
$\mathrm{Hb} \cdot \mathrm{S}$ Val.His.Leu.Thr.Pro.Val.Glu.Lys ....
Hb- $C$ Val.His.Leu.Thr.Pro.Lys.Glu.Lys . . . .
$\mathrm{Hb}-G$ Val.His.Leu.Thr. Pro. Glu.Gly. Lys . . . .
Hb-CGeorgetown Val.His.Leu.Thr.Pro.Glu.Lys.Lys ...

While electrophoretic mobility differences observed among hæmoglobins can be explained by the genetically interchanged amino-acid, a striking property like the phenomenon of sickling cannot be deduced so readily. It appears from the scale-model building experiments that the amino terminal valyl residue interlocks (or intercalates) with the gonetically introduced valyl residue at position 6 in $\mathrm{Hb}-S$ molecule, allowing cyclization of the peptide chain from the carbonyl of the first residue to the $\mathrm{NH}$ of the fourth by hydrogen bonding as shown schematically in Fig. 1.

The intramolecular bond between the valyl side chains and the hydrogen bond as shown in Fig. 1 could stabilize at least 6 residues, thus restricting the freedom of rotation about bonds in the rings thus formed. This is the condition necessary for one of the Kauzmann and Eyring rules which states": "Those influences which tend to restrict freedom of orientation about bonds will tend to increase the order of magnitude of the optical activity". At $0^{\circ}$, 